


\section{La razón de ser de la presencia de Joseph Conrad en El sueño del celta de Mario Vargas Llosa e Historia secreta de Costaguana de Juan Gabriel Vásquez}

Caroline Houde

Investigadora independiente

Resumen:

Este artículo pretende ofrecer un estudio de la influencia actual de la obra de Joseph Conrad en la literatura hispanoamericana por medio del análisis de dos novelas: Historia secreta de Costaguana (2007) de Juan Gabriel Vásquez y El sueño del celta (2010) de Mario Vargas Llosa. En primera instancia, se presenta una visión panorámica del influjo conradiano en la América del siglo XX, tanto por lo que atańe al desarrollo de la crítica poscolonial, como por lo que se relaciona con la representación conradiana del topos de la selva en la narrativa hispanoamericana. Luego, se plantea cómo las dos novelas rememoran ciertos hipotextos conradianos e interrogan el aporte de Conrad a la literatura y al poscolonialismo.

Palabras clave: Joseph Conrad, narrativa hispanoamericana, teoría postcolonial, Mario Vargas Llosa, Juan Gabriel Vásquez. 
Abstract

This article aims to offer a study of the current influence of Joseph Conrad's works in Spanish American literature through the analysis of two novels: Historia secreta de Costaguana (2010) by Juan Gabriel Vásquez, and El sueño del celta (2010) by Mario Vargas Llosa. In first instance, it presents an overview of conradian influence in twentieth-century America, as it regards to the development of post-colonial critique and it relates as well to the conradian topos of the jungle in Spanish American narrative. Then, it observes how the two novels give priority to determined conradian hypotexts and questions Conrad's contribution to Literature and Postcolonialism.

Keywords: Joseph Conrad, Spanish American Narrative, Postcolonial Theory, Mario Vargas Llosa, Juan Gabriel Vásquez.

$\mathrm{D}$ esde la publicación en 1924 de La vorágine por el colombiano José Eustasio Rivera, hasta la de Los pasos perdidos en 1953 por el cubano Alejo Carpentier, la influencia de la obra del escritor polaco-inglés Joseph Conrad y de su obra maestra El corazón de las tinieblas (1899) se ha esfumado paulatinamente de la narrativa hispanoamericana. Sin embargo, dos novelas publicadas recientemente reinventan momentos de la Historia ${ }^{1}$ y rescatan a la figura olvidada de Joseph Conrad: Historia secreta de Costaguana (2007) de Juan Gabriel Vásquez y El sueño del celta (2010) de Mario Vargas Llosa ${ }^{2}$ El siguiente ensayo examina el motivo de ese resurgimiento de Conrad en novelas que tratan, por un lado, de la historia del canal de Panamá y del proceso emancipador de dicho

${ }^{1}$ En el siguiente texto privilegio el uso del término "Historia" para referirme al discurso que narra los hechos del pasado, y la palabra minúscula "historia", como sinónimo de relato.

${ }^{2}$ A partir de ahora utilizo los títulos abreviados Historia secreta y El sueño. 
país y, por el otro, de la vida de Roger Casement, un irlandés que denunció los horrores de la colonia belga en el Congo, en su Informe sobre el Congo (1904), y las atrocidades cometidas en el Putumayo peruano a raíz de la extracción de caucho, en su Libro Azul sobre el Putumayo (1911). Parece ser que ambos relatos, al mismo tiempo que ofrecen una versión relativizada de la Historia, cuestionan el papel de uno de los grandes escritores del canon literario en su denuncia hacia el colonialismo.

\section{Conrad y la herencia americana}

Antes de entrar en el análisis de las dos novelas que me ocupan, quisiera trazar brevemente las principales líneas que ilustran la autoridad de Conrad en la configuración de la teoría poscolonial y que transparentan su aportación al desarrollo de la literatura en América. Por lo que atañe a los discursos que subrayan la influencia del escritor polaco-inglés en el establecimiento de la crítica americana, Perry Miller en Errand to Wilderness (1956) afirma que los estudios americanos habrían nacido en las orillas del Congo de Conrad (Mallios, 2010: 3). El influjo conradiano también se percibe en obras de Faulkner y, de forma explícita, en la película Apocalypse Now (1979) de Francis Ford Coppola, en donde el director traslada la problemática del colonialismo belga en el Congo a la Guerra de Vietnam (Mallios, 2010: 335).

En lo que se refiere a los teóricos del poscolonialismo, Edward Said publica en 1966 su libro Joseph Conrad and the Fiction of Autobiography en el que estudia las cartas de Conrad y observa un cambio en la obra del escritor a raíz de la Primera Guerra Mundial, su apoyo al imperio británico reafirmado y su rechazo hacia Alemania: 
I was able to discover, recorded in the letters, a curious phenomenon in Conrad's life. This was the creation of a public personality that was to camouflage his deeper and more problematic difficulties with himself and his work. The intellectual and spiritual climax of the letters - when they are considered as Conrad's personal history - coincided not only with the fulfilment of his desire for self-discovery, but also with the climax of an important phase of European history: this is the period of the World War One (2008: xIX-Xx).

La revisión de los escritos de Conrad y de su relación con el imperio británico, no sólo por Said, sino por autores como Acheraïou, Lee y Mallios, da cuenta de esa conversión con el paso del tiempo del escritor inglés en "figura especulativa” (Mallios, 2010: 6) y evidencia la ambigua categorización del autor y de su obra literaria a partir de la dicotomía colonialista/anticolonialista. En este sentido, Robert F. Lee interroga el supuesto anticolonialismo de Conrad al afirmar que: "One of the major directions of Conrad's fiction is a recognition of and an accord with the conception of Anglo-Saxon superiority in administering lives of Oriental and other dependant people" (1969: 10). Por su parte, Acheraïou matiza la crítica anticolonial en Conrad, al subrayar lo siguiente: "Notwithstanding his caustic critique of the Belgian empire Conrad does not envisage a post-imperial Africa" (2008: 116). Se puede entonces notar un distanciamiento entre la entidad real del escritor y la ambigüedad interpretativa de su obra, por un lado, y el apoderamiento de su nombre para justificar postulados anticoloniales o, al contrario, para reafirmar la vigencia de la temática colonial en el pensamiento de Conrad, por el otro.

En lo que concierne a la resonancia de la ficción conradiana en la literatura hispanoamericana del siglo XX, la selva de El corazón de las tinieblas —esto es, esa visión de la naturaleza como topos que corrompe al hombre- ha dejado su marca en ciertos 
cuentos del uruguayo Horacio Quiroga, así como en La vorágine del colombiano José Eustasio Rivera y El inglés de los güesos del argentino Benito Lynch, ambas publicadas en los años veinte. Dicha influencia ha sido estudiada, entre otros, por Jennifer L. Lynch en su libro Nature, Neo-Colonialism, and the Spanish American Regional Writers (2005). Por su parte, el cubano Alejo Carpentier, en Los pasos perdidos (1953), y el argentino Jorge Luis Borges, en su cuento "Guayaquil" (Borges, 1979), hacen culminar las huellas del "Gran escritor" inglés en la narrativa hispanoamericana. En efecto, Carpentier retoma en su novela el pretexto del viaje en un río hacia las profundidades de la selva para discutir los efectos del progreso en América Latina, y su capital suramericana anónima no deja de remitirnos al Sulaco de la novela conradiana Nostromo. ${ }^{3}$ Borges, en su cuento "Guayaquil", trata de una supuesta carta escrita por Simón Bolívar, encontrada en la biblioteca del señor José Avellanos, personaje de Nostromo. En dicho relato también aparece el fantasma de Conrad, ahora descrito como el "historiador más famoso del Estado Occidental, el capitán José Korzeniowski” (Borges, 1979: 89), aludiendo a la capacidad del artista, del escritor, para trascender la realidad en los dominios de la imaginación. Tanto en la ficción de Carpentier como en la de Borges, se asiste al uso de la novela conradiana Nostromo para transmitir esencias de la realidad hispanoamericana. En este sentido, Malcolm Deas, en su libro Del poder de la gramática y otros ensayos, formula que dicho texto de Conrad constituye una de las pocas ficciones que logra "realizar el espíritu de toda una época” y que equivale a una de las obras que

${ }^{3}$ Para mayor información sobre la relación de Los pasos perdidos con El corazón de las tinieblas, véase Arturo Echavarría Ferrari: "La confluencia de las aguas : la geografía como configuración del tiempo en Los pasos perdidos de Carpentier y Heart of Darkness de Joseph Conrad” y Eugenio Suárez Galbán Guerra: "Del Congo de Conrad al Orinoco de Carpentier” en Carmen Vázquez (dir.) (2003: $159-170$ y $187-198)$. 
mejor representa los tejemanejes de la vida política hispanoamericana (1993: 269). Asimismo, Ricardo Franco Carpio subraya que se ofrece una reseña directa al personaje de Conrad en El amor en los tiempos del cólera (1985) de Gabriel García Márquez, "cuando se informa que Lorenzo Daza, en nombre del gobierno de Aquileo Parra, había concretado un confuso negocio de armas con 'un tal Joseph K. Korzeniowski, polaco de origen, que estuvo demorado aquí varios meses en la tripulación del mercante Saint Antoine, de bandera francesa'” (Carpio, 2010).

Por lo que atańe a los escritos de los dos autores que aquí nos conciernen, conviene afirmar de entrada que ambos creadores siempre han explicitado su gran atracción hacia la obra literaria de Conrad. Así, Efraín Kristal, en The Temptation of the World, nos revela que los tres autores favoritos de Vargas Llosa son Flaubert, Faulkner y Conrad (1998: 28). Con respecto al influjo particular de Conrad, cabe decir que el tema de la selva entrelazado con el del alma humana son tópicos que Vargas Llosa explora a lo largo de su novelística, pero sobre todo en La casa verde y El hablador. También ha sido demostrado el paralelo entre la caracterización del personaje de Fushía en La casa verde y el de Kurtz en El corazón de las tinieblas (Kristal King, 2012: 142). Por su parte, Vásquez revela su apreciación hacia la obra de Conrad de la siguiente forma en El arte de la distorsión: "yo he encontrado en ciertos novelistas norteamericanos (en particular judíos: vaya uno a saber si eso quiere decir algo), y en ciertos escritores expatriados como Conrad y Naipaul, una forma de narrar la experiencia humana, tanto la individual como la colectiva, que satisface mejor mis necesidades" (2009: 70). La filiación de ambos escritores con Conrad transparenta necesariamente una identificación literaria con determinados textos del novelista inglés. 


\section{Hipotextos conradianos en Historia secreta y El sueño}

Vásquez y Vargas Llosa, ambos grandes admiradores de la obra de Conrad, presentan a la figura de este escritor — entendida esta en una doble acepción que abarca al hombre con implicaciones en el discurso sobre el colonialismo y al autor icónico de las letras del siglo XX- en Historia secreta y El sueño. Esas ficciones se basan en dos textos de Conrad — Nostromo, en el caso de Vásquez, y $E l$ corazón de las tinieblas, en el de Vargas Llosa— para reconstruir sus versiones originales del literato inglés y reflexionar, como lo habré de constatar, acerca del poscolonialismo y del papel trascendental de Conrad en la literatura del siglo XX. En este sentido, la interpretación de la proyección del escritor Conrad y de la influencia de su obra en las dos novelas aquí estudiadas se inscribe en una reflexión mayor sobre la constitución del canon literario y la transformación de Conrad en objeto de especulación para la crítica del poscolonialismo. ${ }^{4}$

Los hipotextos conradianos utilizados en la configuración de ambos relatos no equivalen a meros arrebatos de inspiración momentánea por parte de los escritores, sino que tanto Nostromo como El corazón de las tinieblas parecen orientar la hermenéutica del lector en Historia secreta y El sueño, novelas que permean la autoridad que significa el escritor Joseph Conrad para Vásquez y Vargas Llosa. En este sentido, Vásquez afirma, en El arte de la distorsión, que Nostromo corresponde a la mejor novela, escrita en otra lengua que el castellano, sobre el área latinoamericana y que aparece como uno de los antecedentes más evidentes del "boom" (2009: 147). De forma análoga, la influencia de El corazón de las tinieblas

${ }^{4}$ Por ejemplo, en el estudio de Collits, se demuestra cómo el nigeriano Chinua Achebe promovió en 1975 que se retiraran las obras de Conrad de los currículos académicos, reclamando así un mayor espacio para los autores africanos (Collits, 2005: 83-102). 
en la narrativa vargasllosiana y, más precisamente, en obras como La casa verde se ha estudiado rotundamente (Kristal, 1998: 47). Para estructurar la reflexión sobre el resurgimiento de la figura de Conrad en Historia secreta y El sueño, se ha de examinar primero el eco de los hipotextos conradianos ya mencionados en las dos novelas de Vásquez y Vargas Llosa, para proseguir con el estudio de la proyección del personaje de Conrad en las mismas.

Historia secreta de Costaguana explicita, desde su título, un parentesco con la república ficticia inventada por Joseph Conrad en su novela Nostromo (1904). La trama instaurada por el narrador protagonista José Altamirano nos guía a través dos historias: la mayúscula, que cuenta el largo proceso histórico-político que desemboca en la independencia de Panamá en 1903, y la minúscula, que ofrece al lector un recorrido de la vida de José, desde su nacimiento, hasta el robo de su vida por el gran escritor Joseph Conrad, mismo que utiliza el recuento de Altamirano como inspiración para su novela Nostromo. A primera vista, el relato que nos presenta el narrador parece denunciar la impostura del escritor polaco-inglés, un autor erróneamente ubicado en el pedestal de los grandes del canon, como lo atestigua el siguiente fragmento:

Digámoslo de una vez: el hombre ha muerto. No, no es suficiente. Seré más preciso: ha muerto el Novelista (así, con mayúscula). Ya saben ustedes a quién me refiero. ¿¿No? Bien, lo intentaré de nuevo: ha muerto el Gran Novelista de la lengua inglesa, polaco de nacimiento y marinero antes que escritor, que pasó de suicida fracasado a clásico vivo, de vulgar contrabandista de armas a Joya de la Corona Británica. Señoras, señores: ha muerto Joseph Conrad. Recibo la noticia con familiaridad, como se recibe a un viejo amigo. Y entonces me doy cuenta, no sin cierta tristeza, de que me ha pasado la vida esperándola (Vásquez, 2010: 13). 
La aparente crítica al escritor Conrad también se extiende a sus técnicas literarias, como en un momento en que, a semejanza del incipit en el Quijote, el narrador se burla de la caracterización de los personajes de Nostromo: "En cierta novela conradiana de cuyo nombre no quiero acordarme, cierto personaje más bien cursi, cierto criollo afrancesado, se pregunta: "¿Qué sé yo de rifles militares?». Y yo, ahora, me pongo del otro lado con una pregunta (perdonen la molestia) harto más interesante: ¿Qué saben los rifles de nosotros?" (Vásquez, 2010: 78). ${ }^{5}$ No obstante estos indicios textuales que constituyen un rechazo a la literatura del "Gran escritor inglés", habré de comprobar que Historia secreta justamente propone lo inverso, esto es, una revalorización de la obra ficticia de Conrad.

En una entrevista realizada en enero de 2014, Vásquez confiesa que Conrad ha ejercido una doble influencia en él, por lo que la lectura de la obra del escritor inglés nutrió su anhelo de escribir, y también porque las ficciones conradianas le subministraron técnicas para redactar novelas (Rebollo, 2014). Un breve vistazo hacia los diferentes peritextos que acompañan la novela evidencia el influjo de Conrad en Historia secreta. Además del título, los cuatro epígrafes que enmarcan el relato se constituyen de tres citas extraídas de Nostromo y de una carta de Conrad a Cunninghame Graham que trata de la elaboración de Nostromo. Estos son los tres fragmentos que encabezan las distintas partes del relato de Vásquez:

Quiero hablarte de la obra que me ocupa actualmente. Apenas si me atrevo a confesar mi osadía, pero la he ubicado en América del Sur, en una República que he llamado Costaguana (Carta a Robert Cunninghame Graham)

5 Efectivamente, en Nostromo el personaje de Martin Decoud se pregunta: "What do I know of military rifles?" (Conrad, 2009: 112). 
No hay Dios en países donde los hombres no se ayudan a sí mismos (Nostromo)

Las palabras que tan bien conocemos tienen significados de pesadilla en este país. Libertad, democracia, patriotismo, gobierno: todas saben a locura y asesinato (Nostromo)

...el nacimiento de otra República sudamericana. Una más, una menos, ¿qué importancia tiene? (Nostromo) (Vásquez, 2010)

Vásquez, en su Historia secreta, no sólo demuestra su admiración por la obra conradiana, al operar una fusión entre la Historia y unos destinos individuales, sino que también emplea una serie de procedimientos literarios propios de la trama narrativa presente en Nostromo. Tal es el caso de las constantes analepsis y prolepsis por medio de las cuales José Altamirano edifica su narración, que remiten a la construcción narrativa de Nostromo. Para impedir que el lector pase por alto el paralelismo entre ambas novelas, el narrador se empeña constantemente en explicitar sus repetidas transgresiones temporales: "La cronología es una bestia indómita; no sabe el lector los trabajos inhumanos por los que he pasado para darle a mi relato un aspecto más o menos organizado" (Vásquez, 2010: 86).

Además de esas equivalencias en el tratamiento del tiempo en las novelas, es posible verificar que tanto Conrad como Vásquez hacen coexistir personajes reales y ficticios en sus relatos. A manera de ejemplo, en Nostromo asistimos al proceso de independencia de Sulaco, el cual cambia el destino de personajes inventados como Martin Decoud, los Gould y Nostromo, pero dentro del cual se inserta a personajes y hechos reales, tales como los viajes de Garibaldi, la invasión de la República mexicana por los franceses en 1861 y las "hazañas" de Bolívar. En Historia secreta, Vásquez construye el recuento ficticio de José Altamirano y de su familia, pero reviste su relato de verosimilitud histórica, al describir con detalles el trasfondo histórico que desembocó en la independencia de Panamá. 
Para hacerlo, Vásquez introduce en su narración reseñas claras a la política colombiana, pero también menciona la estancia de grandes artistas en Suramérica como Melville y Gauguin. La presencia real de ambos en suelo latinoamericano se insinúa de forma fragmentada en Historia secreta. En el caso de Melville, aprendemos en una nota parentética que "Poco antes de morir en Paita, Manuela Sáenz recibió la visita de un gringo medio loco que estaba de paso por el Perú. El gringo, sin siquiera quitarse el sombrero de ala ancha, le explicó que estaba escribiendo una novela sobre ballenas" (2010: 58). El narrador de Historia secreta también nos informa que Gauguin trabajó para la Compañía del Canal: "El hombre era un pobre francés desquiciado que en realidad no era más que un vándalo. Se decía que era pariente de Flora Tristán, lo cual hubiera interesado a mi madre; había desembarcado en Ciudad de Panamá, proveniente del Perú, y allí fue arrestado por orinar en público [...]. Se llamaba Paul Gauguin” (Vásquez, 2010: 176-7).

Además, una de las influencias conradianas más marcadas en Historia secreta, pero también en toda la formación de Vásquez como escritor, se centra en una postura de un autor que admite discurrir sobre "asuntos oscuros", zonas y espacios que no entiende perfectamente. Es un hecho demostrado que Conrad escribió su novela Nostromo sin haber realmente pisado la tierra latinoamericana, salvo cuando pasó cerca de las costas de Venezuela y Colombia cuando joven (Conrad, 2009: xxi). Para informarse sobre el continente, Conrad tuvo que acudir a su amigo Cunninghame Graham, quien le detalló las tierras que conoció y le recomendó lecturas (Conrad, 2009: xxi). A semejanza de Conrad, Vásquez confiesa en una entrevista a Jorge Ruffinelli que Colombia siempre representó para él un tema oscuro:

And it took me some years and some novels that I read, and the discovery of some authors - Philip Roth was one of them, Joseph Conrad was the most important of them all — to discover that 
not understanding my country was precisely the best reason to write about it. The idea that literature is a discovery, an act of inquisition, You ask questions. You don't write because you know, you write in order to know, in order to find out. At that moment I found out that I'm allowed to write about my country, about Colombia. I am allowed to treat Colombia as this dark place that I don't understand but because I don't understand it I am going to write about it (Ruffineli, 2013/2014: 154).

Esta postura creativa de Vásquez también aparece detallada en su concepto de "literatura de inquilinos", una escritura que promueve el descubrimiento de "territorios desconocidos o inexplorados" para el autor que indaga acceder a una iluminación (Vásquez, 2009: 185). Vásquez consigue dicha iluminación al encontrar en su revisión del proceso de emancipación de Panamá una crítica al imperialismo económico norteamericano y un cuestionamiento sobre la aparente oposición: civilización europea/barbarie americana, dos temáticas ya presentadas en Nostromo.

La influencia conradiana en Historia secreta no sólo se percibe al señalar sus paralelismos con Nostromo, sino que también se vislumbra con la presencia de una temática explorada por Conrad en su cuento "El compañero secreto" (1910): el doble. ${ }^{6}$ Efectivamente, José Altamirano señala en varias ocasiones que él y Joseph Conrad son almas gemelas, doppelgänger (Vásquez, 2010: 59-60), y evidencia las similitudes de sus edades, de sus identidades dobles -Korzeniowski/Conrad, por un lado, y Narváez/Altamirano, por otro lado-, de sus destinos vitales (África y Panamá) y hasta de sus encuentros fortuitos en distintas geografías. Así, Altamirano cuenta cómo los dos gemelos se cruzan en 1876, cuando Korze-

${ }^{6}$ El tema del doble abarca gran parte de la novelística de Vásquez. En Los informantes, el narrador Gabriel Santoro tiene el mismo nombre que su padre, haciendo que la coincidencia homónima convierta el título en una ambigüedad significativa. 
niowski trabaja en el barco Saint-Antoine y viene a vender armas a los conservadores colombianos, y en 1903, momento en el que José le relata su vida a Conrad y que este le roba su historia, su alma. El filósofo francés Clément Rosset explica, en Lo real y su doble (1976), que la búsqueda identitaria implica un exorcismo, el del otro, para que el individuo pueda reconocerse:

El autoreconocimiento, que implica una paradoja en sí (puesto que se trata de comprender lo que, justamente, es imposible comprender, y que el hacerse cargo de sí mismo reside paradójicamente en la renuncia a esa toma de control), también supone necesariamente un exorcismo: el del doble, que obstaculiza la existencia de lo único y que exige que este último no sea nada sino el mismo, y nada más (1994: 97; la traducción es mía). ${ }^{7}$

Es justamente el procedimiento empleado por Altamirano en Historia secreta para dar existencia a su historia minúscula, puesto que él y Conrad aparecen como "dos encarnaciones de un mismo José, dos versiones del mismo destino" (Vásquez, 2010: 59). Como una especie de venganza operada en su novela, frente a la lectura de la obra de un inglés que ha escrito sobre América del Sur sin haber realmente conocido el continente, Vásquez le inventa un nuevo destino al "Gran escritor". No obstante, esa revancha de Vásquez se convierte en engaño al lector en la nota del autor al final del la novela. Efectivamente, en ese espacio Vásquez establece una lista de las obras que lo han influenciado para la creación de su Historia secreta. Entre ellas, se encuentra la obra de un tal José Avellanos, personaje ficticio de Nostromo, titulada History of fifty years of misrule, dejando ver que ese título imaginado por Conrad, lejos de

${ }^{7}$ De manera semejante, Edward Said afirma, al tratar de tema del doble en "El compañero secreto", que el relato "contains, then, the double working out and rescue that Conrad now saw as the momentary salvation for his embattled self" $(2008: 131)$. 
ostentar la ignorancia del escritor frente a la geografía suramericana, transparenta una comprensión íntima de la vida política en América del Sur y, más particularmente, Colombia. ${ }^{8}$

De esta forma, Vásquez se adecua a la visión borgiana de Nostromo descrita en el cuento "Guayaquil" (1970), en el que la biblioteca del personaje de Avellanos le permite a Borges conjeturar sobre el pasado y reclamar una mejor comprensión de la Historia por medio de la ficción. En este sentido, Vázquez en su Historia secreta patentiza la coincidencia cronológica de dos momentos: la escritura, en 1899, de una carta de Conrad a Cunninghame-Graham en donde le dice que "El hombre es un animal malvado [...]. El crimen es una condición necesaria de la existencia organizada. La sociedad es esencialmente criminal" (2007: 201), y el inicio, el mismo ańo, de "la guerra civil más larga y sangrienta de la historia de Colombia” (2007: 201). El narrador Altamirano subraya la trascendencia de los escritos de Conrad, un ser que, para él, vislumbró, más allá de toda reducción geográfica, la naturaleza salvaje del ser humano y el carácter impetuoso de la sociedad.

Si en Historia secreta la ficción conradiana que mayor proyección e influencia tiene es Nostromo, en El sueño de Vargas Llosa el texto conradiano que acompaña la conformación del relato es El corazón de las tinieblas. Cabe decir de entrada que la presencia de la figura del escritor Conrad en El sueño del celta no es tan sustancial en términos de porcentaje de texto ocupado como en la novela de Vásquez. En un espacio de pocas páginas, Vargas Llosa logra poner en tela de juicio la herencia de la obra maestra que representa El corazón de

${ }^{8}$ Dicha maniobra de Vázquez llega hasta a engañar a sus críticos. En efecto, Ricardo Franco Carpio ańade, en la lista de las obras citadas de su artículo titulado "Espejos, simulacros y distorsiones: Hacia una tipología de la 'metaficción historiográfica' en Historia secreta de Costaguana, de Juan Gabriel Vásquez", el nombre de un libro curioso: AVELLANOS, José. (1939). Cincuenta años de desgobierno. Sulaco: El Porvenir. 
las tinieblas, por medio de una conversación entre Roger Casement y Alice Stoppford Green (una reconocida historiadora nacionalista irlandesa) cuando ésta visita a Casement en la cárcel. Stoppford Green aclara que la parábola en El corazón de las tinieblas se reduce a la percepción del espacio africano como topos que corrompe al hombre. En contraposición a la novela de Conrad, Stoppford señala que Casement, al regresar del Congo, era un hombre más civilizado que antes y pudo denunciar los errores cometidos por los europeos en su Informe sobre el Congo. Tras una breve reflexión y la apreciación del valor literario de El corazón de las tinieblas, el propio Casement afirma lo siguiente a propósito del texto de Conrad: "Yo creo que no describe el Congo, ni la realidad, ni la historia, sino el infierno. El Congo es un pretexto para expresar esa visión atroz que tienen ciertos católicos del mal absoluto" (Vargas Llosa, 2010: 77). En El sueño se menosprecia entonces, a primera vista, el aporte de la novela maestra de Conrad al beneficio de los informes redactados por Casement como críticas al colonialismo.

Sin embargo, la aparente desvalorización de la obra maestra de Conrad en El sueño disimula una filiación temática con El corazón de las tinieblas. John King revela que Vargas Llosa dijo, al analizar esta ficción de Conrad, que "the novel is an exploration of the roots of humankind, 'those inner recesses of our being which harbour a desire for destructive irrationality that progress and civilisation might manage to assuage but never eradicate completely' (Kristal y King, 2012: 160). Es justamente este tópico entre el idealismo civilizador y el colonialismo económico en el Congo y el Putumayo lo que guía la vida del Casement vargallosiano, como lo atestigua este fragmento: "El Congo. La Amazonía. ¿No había pues límites para el sufrimiento de los seres humanos? ¿El mundo estaba plagado de esos enclaves de salvajismo que lo esperaban en el Putumayo. ¿Cuántos? ¿Cientos, miles, millones? ¿Se podía derrotar esa hidra?” (Vargas Llosa, 2010: 163). En fin, como en 
El corazón de las tinieblas, Vargas Llosa ahonda la exploración del tema de la selva, entendida ésta no como topos propicio para el desarrollo de la barbarie, sino como implicación del alma humana, una zona de tinieblas que requiere civilización para salvarse.

\section{Conrad o del (anti)colonialismo}

A raíz de mi breve incursión en la representación de los hipotextos conradianos en las dos novelas aquí analizadas, conviene ahora interrogarme sobre el eventual cuestionamiento de Conrad como denunciador del colonialismo en Historia secreta y El sueño. A primera vista Józef Teodor Konrad Korzeniowski, por su origen polaco y el patriotismo de su padre en contra del imperialismo ruso, parece ser el hombre predilecto para oficiar como portaestandarte de toda crítica hacia el colonialismo. ${ }^{9}$ No obstante, ciertos elementos desvelados en las líneas de Historia secreta y El sueño resaltan elementos de la biografía conradiana que ponen en tela de juicio dicha afirmación y refuerzan el vínculo del escritor con el imperio británico. ${ }^{10}$ Así, en Historia secreta nos enteramos de que Conrad adopta la nacionalidad inglesa y empieza a firmar con su nuevo nombre en 1886 a raíz de su estancia en Calcuta (India), colonia británica (Vásquez, 2010: 164). Sin embargo, la mayor crítica hacia la relación de Conrad con el imperio de Inglaterra aparece en El sueño, cuando aprendemos que el gran escritor inglés rechaza

9 Para mayor información sobre el origen de Conrad, acudir a la biografía del escritor inglés realizada por Vásquez: Joseph Conrad: el hombre de ninguna parte (2007).

${ }^{10}$ Conrad, a pesar de haber denunciado el colonialismo belga en el Congo, mantuvo una actitud prudente hacia el imperio británico. A manera de ejemplo, después de haber aceptado el calificativo de "anti-imperialista" para su novela $E l$ corazón de las tinieblas, Conrad rechazó una invitación para participar en una actividad política para oponerse a la guerra de los bóeres en Suráfrica (Collits, 2005: 105). 
apoyar a su amigo Roger Casement al negarse a firmar el pedido de clemencia que le perdonaría la vida por haber participado en el sublevamiento nacionalista en Irlanda, en contra de la autoridad británica (Vargas Llosa, 2010: 70).

Además de objetarse la etiqueta de "denunciador del colonialismo y del imperialismo" (asignada a priori a Conrad por su nacionalidad de origen y su obra maestra, El corazón de las tinieblas, que detalla los excesos del colonialismo belga en el Congo), en ambas novelas se avanza que Conrad construye sus relatos desde la perspectiva del europeo. En este sentido los juicios emitidos en las ficciones de Vásquez y Vargas Llosa en contra del aporte de Conrad en su rol de gran denunciante del colonialismo encuentran eco en el pensamiento de teóricos del postcolonialismo como Said y Bhabha. Recordemos que tanto Said, en El orientalismo (1978), como Bhabha, en El lugar de la cultura (1994), revelan que varios europeos, que en el siglo XX quisieron representar al "otro", nunca ubicaron al extranjero en la posición de agente activo de la articulación del discurso, y privilegiaron muchas veces el estereotipo y la confrontación polémica como modelos de configuración, o, como lo expresa el mismo Bhabha: "El déspota turco de Montesquieu, el Japón de Barthes, la China de Kristeva, los indios nambikwara de Derrida, los paganos cashinahua de Lyotard, son parte de esa estrategia de contención donde el texto Otro es siempre el horizonte exegético de la diferencia, nunca el agente activo de la articulación (2002: 52). ${ }^{11}$ En este sentido, las dos ficciones aquí analizadas presentan a Conrad como un ladrón de historias ajenas. De hecho,

${ }^{11}$ Por su parte, Said en El Orientalismo postula lo siguiente: "Con la bibliografía perteneciente a estas experiencias se construye un archivo internamente estructurado. De lo cual surge una cantidad restringida de encapsulamientos típicos: el viaje, la historia, la fábula, el estereotipo, la confrontación típica. Esos son los lentes a través los cuales se experimenta el Oriente, y conforman el lenguaje, la percepción y forma del encuentro entre Este y Oeste" (apud Bhabha, 2002: 98). 
Altamirano en Historia secreta señala que Conrad le ha usurpado su identidad, su historia, y el mismo personaje de Conrad en $E l$ sueño le revela a Casement que éste debió de figurar como coautor de El corazón de las tinieblas (Vargas Llosa, 2010: 74). Frente a dos novelas que señalan la colonización del imaginario literario operada por Conrad con sus obras, las cuales pretenden retratar al otro, pero desde la perspectiva del europeo, los personajes de Altamirano y Casement surgen para cuestionar esa ficción orientada, estereotipada.

A raíz del examen de las ficciones estudiadas, puedo aventurarme a conjeturar que la influencia de la obra conradiana en la narrativa hispanoamericana ha cambiado de rumbo. En vez de presentar unas selvas que corrompen el alma humana a semejanza de Conrad, tanto Historia secreta como El sueño privilegian una nueva visión de los estragos del colonialismo y del imperialismo económico, pero desde perspectivas inéditas. Sin embargo, estos enfoques originales, que apuntan a nuevas figuras como portadoras de la denuncia colonialista, también se ven contaminados por los archivos europeos y sus construcciones estereotipadas. Así, José Altamirano, en Historia secreta, no se reconoce como colombiano, ni como panameño, y acaba su vida en Londres, lejos de su hija, donde reconstruye su historia desde el mismo imperio en el que se refugió Conrad; por su parte, Roger Casement, si bien denuncia los horrores del colonialismo en el Congo belga y el Putumayo peruano, lo hace desde la perspectiva del observador externo, del extranjero. En este sentido parece relevante la afición de fotógrafo de Casement, que en El sueño del celta saca retratos de los cuerpos bronceados de los jóvenes. Weldt-Basson propone que esa perspectiva del personaje reproduce la actitud ambivalente del colonizado descrita por Bhabha, por medio de un proceso mediante el cual se estereotipa y se convierte en fetiche al otro (2013: 236). 
Dichas presentaciones que cuestionan el papel de Conrad como "escritor anticolonialista" también se insertan en el debate acerca de la conversión de Conrad en figura de especulación con el tiempo y proponen, al retomar a la figura de Conrad y su obra, una nueva ética del escritor que reclama una libertad más allá de cualquier discurso de pretensión dicotómica. Efectivamente, como afirma Collits al relatarnos un discurso de Chinua Achebe en donde el escritor nigeriano reclamaba la supresión de la obra de Conrad de las lecturas académicas por su representación equívoca del otro, "Instead of being banished from the curriculum [...], Conrad's place was reaffirmed, althought with new terms of reference. The close attention given to all Conrad writings in turn encouraged readers to deconstruct the binary structures of racist discourse" (Collits, 2005: 101).

Tras haber cartografiado la presencia de Conrad y de su obra en las dos novelas y rastreado su significado, parece importante recordar — a modo de apertura, o quizás, para señalar una contradicción en las múltiples paradojas que Historia secreta y El sueño proponen- que estas dos nuevas historias de la independencia de Panamá y de la explotación del caucho en el Putumayo peruano se escriben en España, antiguo imperio español. Precisamente, Vásquez concluye la escritura de su novela en Barcelona - firma su obra en "Barcelona, mayo de 2006" (2010: 292) — y Vargas Llosa la termina en Madrid-o, así lo evidencia en la marca que cierra su texto: "Madrid, 19 de abril de 2010" (2010: 451)—. En este sentido, tanto Vásquez como Vargas Llosa se posicionan en el lugar de Conrad y nos invitan a reconsiderar nuestra apremiada lectura de Historia secreta y El sueño como simples críticas hacia la figura del escritor inglés. La advertencia que ambos escritores formulan, desde la trascendencia de sus posicionamientos geográficos, es que la escritura en el área hispanoamericana es producto de influencias externas, muchas veces europeas, y que se ha de asumir esta heren- 
cia. También señalan la naturaleza particular de la obra literaria, desvinculada de las acciones del escritor, libre de toda construcción doctrinaria y exenta de cualquier intento de reducción binaria de su significado.

En síntesis, el distanciamiento entre la obra de Conrad y sus escritos también se puede asociar con la escisión que se opera entre la figura pública de Vargas Llosa y sus novelas. De hecho, comparto la siguiente reflexión de Sabine Köllmann acerca del escritor peruano: "Love his fiction, hate his politics' — this statement could sum up the attitude held by many readers of Mario Vargas Llosa's novel on the one hand and, on the other, his comments on current affairs that he publishes in journals in Europe and the Americas" (2010: 173). Asimismo, la distinción entre la narrativa de Vásquez y su existencia cotidiana se halla en que la primera se centra en la representación del territorio colombiano, mientras que su vida, hasta hace poco, el autor la construyó en el exterior. En un ensayo titulado "Literatura de inquilinos", Vásquez intenta justificar la necesaria separación del escritor con lo conocido: "la novela es un género inquisidor, un género que funciona mejor cuando se adentra en territorios desconocidos o inexplorados, cuando lleva a cabo una averiguación, una iluminación” (2009: 185). Si bien parece acertado en el caso de Conrad, la literatura de inquilinos que tanto inspira la pluma de Vásquez no es la que lo lleva a expresar asuntos nacionales, por oposición a geografías extranjeras, sino que dicha sensación momentánea que resiente el escritor delante del espacio representado en su ficción viene a reflejar una tendencia actual del "estar en el mundo", en donde la existencia transnacional desubica al ser y lo convierte en extraño, en un ser de ninguna o todas partes. $^{12}$

${ }^{12}$ De manera semejante, Vargas Llosa afirma en una entrevista a Raymon Leslie Williams: "We now live in a period in which terms such as 'an American', 'a Latin American' or an 'European' can no Langer be considered isolated entities 


\section{Bibliografía}

Acheraïou, Amar, 2008, Rethinking Postcolonialism: Colonialist Discourse in Modern Literatures and the Legacy of Classical Writers, New York, Palgrave Macmillan.

Bhabha, Homi K., 2002, El lugar de la cultura, César Aira (trad.), Buenos Aires, Manantial.

Borges, Jorge Luis, 1979, "Guayaquil", en El informe de Brodie. Historia universal de la infamia, $2^{a}$ edición, Barcelona, Ediciones G.P., pp. 87-98.

Carpio Franco, Ricardo, 2010, "Espejos, simulacros y distorsiones: Hacia una tipología de la 'metaficción historiográfica' en Historia secreta de Costaguana, de Juan Gabriel Vásquez", Espéculo, núm. 44, 2010.

Collits, Terry, 2005, Postcolonial Conrad: Paradoxes of Empire, New York, Routledge.

Conrad, Joseph, 2005, Le compagnon secret. The Secret Sharer, ed. bilingue, G. Jean Aubry, (trad.), Sylvère Monod (pref. y notas), París, Gallimard (Folio 127).

, 2009, Nostromo, Jacques Berthoud y Mara Kalnins (ed. intro y notas), Oxford, Oxford University Press.

Deas, Malcolm, 1993, Del poder y la gramática y otros ensayos sobre historia, politica y literatura colombianas, Bogotá, Tercer Mundo Editores.

French, Jennifer L., 2005, Nature, Neo-Colonialism, and the Spanish American Regional Writers, Hanover, Darmouth College Press (Reencounters with Colonialism: New Perspectives on the Americas).

[...]. Today, I believe, it is almost impossible not no be a citizen of the world" (apud Williams: 2014, 205). 
Köllmann, Sabine, 2010, "Vargas Llosa's Self-Definition as 'The Man who Writes and Thinks", en Vargas Llosa and Latin American Politics, Juan E. de Castro y Nicholas Birns (eds.), Nueva York, Palgrave Macmillan, pp. 173-88.

Kristal, Efrain, 1998, Temptation of the World: The Novels of Mario Vargas Llosa, Nashville, Vanderbilt University Press.

y John King, 2012, The Cambridge Companion to Mario Vargas Llosa, Cambridge, Cambridge University Press.

Lee, Robert F., 1969, Conrad's Colonialism, The Hague/Paris, Mouton.

Mallios, Peter Lancelot, 2010, Our Conrad: Constituting American Modernity, Stanford, Stanford University Press.

Pérez Triana, Santiago, 1897, De Bogotá al Atlántico por la vía de los ríos Meta, Vichada y Orinoco, Paris, Sudamericana.

Rebollo, Esther, 2014, “Juan Gabriel Vásquez confiesa que sus novelas son enseñanzas de Joseph Conrad”, disponible en Lainformación.com (consultado el 25/I/2015).

Rosset, Clément, 1994, Le réel et son double: essai sur l'illusion, ed. revisada y aumentada, París, Gallimard (Folio essais 220).

Ruffinelli, Jorge, 2013/2014, "Juan Gabriel Vásquez. History, Memory and the Novel", Nuevo Texto Critico, v. 26, t. 7, núm. 49-50, pp. 151-163.

Said, Edward, Joseph Conrad and the Fiction of Autobiography, foreword by Andrew N. Rubin, New York, Columbia University Press, 2008.

Vargas Llosa, Mario, 2010, El sueño del celta, Buenos Aires, Alfaguara.

Vásquez, Carmen (dir.), 2003, Alejo Carpentier et Los pasos perdidos, París, Indigo et Côté-femmes éditions. 
Vásquez, Juan Gabriel, 2009, El arte de la distorsión, Madrid, Alfaguara.

, 2010, Historia secreta de Costaguana, Bogotá, Alfaguara.

, 2007, Joseph Conrad: el hombre de ninguna parte, Barcelona, Norma.

,2004, Los informantes, Madrid, Santillana.

Weldt-Basson, Helene Carol, 2013, "El sueño del celta: Postcolonial Vargas Llosa", en Redefining Latin American Historical Fiction: The Impact of Feminism and Postcolonialism, Helene Carol Weldt-Basson (ed.), Nueva York, Palgrave Macmillan, pp. 23148.

Williams, Raymon Leslie, 2014, Mario Vargas Llosa: A Life of Writing, Austin, University of Texas Press.

(Recibido: 14 de noviembre de 2014, aceptado: 23 de marzo de 2015) 